\title{
"A Study on Serum Amylase Level And Prevalence of Acute Pancreatitis in Organophosphate Poisoning"
}

\author{
1. Dr Kumar Pankaj Shah, ${ }^{2}$ Dr M Rajkumar Md (Gen Med), \\ 3. Dr S Senthur Raja Pandian, Md (Gen Med), Dm (Neuro), \\ 4. Dr C Dharmaraj Md (Gen Med), Dch \\ ${ }^{1}$ Senior Resident, Dept Of Medicine, Govt Rajaji Hospital \& Madurai Medical College, Madurai \\ ${ }^{2}$ Senior Assistant Professor of Medicine, Govt Rajaji Hospital \& Madurai Medical College, Madurai \\ ${ }^{3}$ Asst Professor of Medicine, Govt Rajaji Hospital \& Madurai Medical College, Madurai \\ ${ }^{4}$ Associate Professor of Medicine, Govt Rajaji Hospital \& Madurai Medical College, Madurai
}

\section{Introduction}

Acute organophosphate poisoning is one of the commonest poisoning and have reached epidemic proportion in most parts of the world especially in developing countries, where the toxicity of poison and its medical management is lacking and leads to its high fatality rate.

Their ease of access and socio-cultural factors play important role in the choice of OP as a self-poison and the incidence is higher in younger, economically active group with a case fatality ratio of 20.

According to WHO, world wide estimates of pesticide poisoning number 3 million each year, with 2 million hospitalized from suicide attempt and 2,20,000 death, the majority of which are actually intentional.

Poisoning due to occupational exposure, accounted for about one fifth of the incident with a fatality ratio of less than 1 . More than $90 \%$ of the non-occupational incidents were suicidal, with a fatality ratio more than $10 \%$ and the majority of the subjects are young male.

Accidental exposure accounted for $8-10 \%$ of the incident and homicidal use (less than $1 \%$ ) were others form of poisoning. The reported over all mortality following OP insecticide poisoning caries from $4-30 \%$ in different countries.

In India, OP compounds causes more self poisoning death in southern and central india. In northern India, aluminium phosphate causes most death with a fatality ratio over 90 . Other pesticides used for self poisoning include carbamates, organochlorine and pyrethroid. Organophosphorous compound are principally used as pesticides and their exposure is highly prevalent in developing countries.

Toxic effect of OPs are associated with significant morbidity and mortality and are a major global clinical problem.

Occupational, suicidal, homicidal exposure to OPs produces characteristics symptoms but treatable in human thus early recognition and timely intervention of toxicity from this compounds are of great importance to emergency physicians and patients.

Case report on acute pancreatitis following acute OP compound ingestion has been reported now and then, but regular studies with reference to the pancreatitis in not available in a serial manner. Hence an attempt was made to study pancreatic involvement through biochemical means.

\section{Aim Of The Study}

1) To estimate serum amylase level and prevalence of acute pancreatitis in organophosphate poisoning.

2) To find out its relationship with

a) Clinical severity

b) Outcome

\section{Review Of Literature}

- Origins of serum aymlase :

So many organs and secretions in human have amylase activity like

- Pancreas

DOI: $10.9790 / 0853-1509067198$

www.iosrjournals.org

$71 \mid$ Page 
- Salivary gland

- Fallopian tube

- Lungs tissues

- Thyroid gland

- Tonsils

- Breast milk

- Sweat gland

The amylase concentration is much more greater in pancreatic gland secretion and salivary gland secretion as compare to other gland secretion in body. To maintain steady level of amylase in serum higher secretion is required and it is very unlikely to have such higher secretion of amylase other than the organ listed above.This has been clearly evidenced by electrophoreticstudies of normal serum.As per Electrophoretic studyit is of two types :

1) P-type from the pancreatic gland

2) S-type from the salivary gland

Other secretions like in fallopian tube, breast milk secretion, sweat gland secretion have similar electrophoretic property to salivary iso-amylase. Almost all S-type iso-amylase belongs to salivary gland.

\section{- Fate of serum amylase :}

The metabolism of serum amylase are not clearly known till now.Human who had gone through nephrectomy or have kidney disease have serum amylase level fifty percent greater than normal persons. So kidney can play a important role in amylase clearance. Although, kidney is not the major organ for amylase metabolism in individuals. Other mechanism other than renal clearance of amylase have not been explained. But in some liver pathology for example cirrhosis, hyperamylasemia has been reported, so we can assume that liver also play some role in amylase clearance from the body.

\section{- $\quad$ Factors affecting serum amylase level :}

Many possibilities responsible for increased amylase level. Although increase amylase is commonly occurs due to secretion of amylase into the serum by the diseased organ, the relationship between increased amylase and the exact pathology is not entirely known. Increased amylaseis seen in

1) Inflammatory condition of pancreas

2) Parotitis

3) Decreased metabolic clearance of amylase

4) Diseased organ secret more amylase

\section{Pancreatic Pathology -}

\section{Etiology of hyperamylasemia}

Acute or chronic pancreatitis is related with raised level in the P-type iso-amylase. In acute pancreatitis, serum amylase level usually elevated 6-times than the normal amylase and then come to normal by three to seven days. Patient associated with pancreatic inflammation with increased triglyceride level or those associated with acinar cell injury because of previous episodes of pancreatic disease or chronic pancreatic inflamation may not show increased amylase level. Other reasons for increased amylase that are associated with pancreatitis :

1) pseudocyst of pancreas

2) pancreatic ascites

3) trauma to pancreatic gland

4) choledocholithiasis

Trauma to pancreatic gland can be seen in blunt trauma, abdominal or retroperitoneal surgery,or endoscopic retrograde cholangio pancreatography

(ERCP).Trauma seen in ERCP is due to regurgitation of amylase into the blood, can be seen in $75 \%$ patients of ERCP, but mostly patients have no evidence of pancreatic trauma.A three to four times elevated in serum amylase level 4 hours of ERCP anticipate the possibility of complicating pancreatitis after ERCP. If patients complaining colicky type of abdominal pain, and a three times elevated serum amylase level that come to normal within 48-72 hours suggestive of stone passage through the CBD. 


\section{- Salivary gland disease :}

Parotitis, a inflammatory condition of parotid gland is associated with elevated in S-type iso-amylase. Parotitis is commonly due to trauma to salivary gland or surgery to the salivary gland, radiation to head and neck area especially to the parotid gland, subsequently causes duct obstruction, or formation of stone in the salivary duct. Other cause of damage to salivary gland include chronic alcohol intake. Salivary amylase level are three times more than normal in $10 \%$ of alcoholic, this may be because of chronic liver disease.

\section{Metabolic clearance :}

Renal failure leads to elevated S-type and P-type iso-amylase. Liver pathology due to hepatitis or cirrhosis can also result in elevated S-type and P-type iso-amylases.

Macroamylasemia ( large size amylase ) is a benign condition in which the amylase molecules attached with large complex molecules like immunoglobulin, polysaccharide etc. increases the half life and decreases its clearance through kidney. About two to five percent of patients with increased amylase levelhave macroamylasemia.

\section{Gastro-intestinal tract ( git )diseases :}

GIT disease, like mucosal inflammatory condition of the small intestine, mesenteric infarction, obstruction of intestine, inflammatory condition of appendix, and inflamed peritonium, commonly results in elevated P-type isoamylase because of elevated absorption of amylase from the GIT lumen. GIT perforation leaks the intestinal contents to the peritoneum causes inflammation and increased absorption of amylase through the inflamed peritoneum. This can result in increased amylase level.

\section{Female reproductive tract disease :}

Ruptured ectopic pregnancy, fallopian tube or ovarian cysts, and salpingitis can leads to elevated S-type isoamylase.

Miscellaneous causes :

Ectopic amylase production like

- Lungs

- Ovary

- Malignancy of colon

- Adrenal gland tumor especially pheochromocytoma

- Thymoma

- Plasma cell tumor or Multiple myeloma

- Breast cancer

\section{- Laboratory significance :}

The commonly used application of serum amylase is to help in diagnosis of acute pancreatitis. In acute pancreatitis, the serum amylase is elevated to usually 6 times in atleast $75 \%$ of patients on the first day of symptoms, then, it usually comes to normal by three to seven days. The specificity of the test increases with higher level of enzyme.

Serum amylase parameter is not so sensitive or specific to pancreatic gland injury because it can be normal in patients with pre-existing acinar cell injury or chronic pancreatitis and so many other etiologies of increased amylase level are explained previously. Patient with asymptomatic chronic increased amylase level almost never has pancreatic pathology as the cause of increased amylase level. For mild elevated serum amylase level, other methods can be used to know the etiology of increase amylase level.

The amylase-creatinine clearance ratio (ACR ) helps to differentiate acute pancreatitis from other conditions. This can to done with the help this formula

\section{$\mathbf{A C R}=($ amylase$[$ urine $] \mathrm{X}$ creatinine $) /($ amylase[serum $]$ Xcreatinine[urine $] \mathrm{X} 100$}

An ACR of more than $5 \%$ suggest acute pancreatitis. It can be elevated in diabetic ketoacidosis, renal pathology and post-operative conditions. An ACR of less than one percent signify macroamylasemia(large size amylase ). Amylase secretion in urine are relatively non-specific, so the calculations to know the level of urinary amylase excretion have no clinical use. Generally the ACR measurement has been abandoned, except some special 
condition to confirm a diagnosis of macroamylasemia, which is characterized by a low ACR. A lipase-to-amylase ratio of greater than two may suggest alcoholic pancreatitis, but it is not a reliable predictor of alcoholic pancreatitis. Serum iso-amylase calculation to know S-type iso-amylase, P-type iso-amylase, or macroamylasemia are the good parameters to use when the cause of increased amylase obscure.

\section{Organophosphate - a background}

The clinical features of OP Poisoning are due to the increased Synaptic deposition of acetylcholine (ACh ). OP compounds, irreversibly stop the enzyme cholinesterase $(\mathrm{ChE})$ which result in increased deposition of Ach, leads to the decreased cholinergic flow in

1) $\mathrm{CNS}$

2) Autonomic ganglia

3) Parasympathetic nerve endings

4) Some sympathetic nerve endings

5) Neuromuscular junctions

\section{Toxicokinetics :}

OP agents and carbamates are generally highly lipid soluble and can lead to systemic absorptionsand can lead to toxic symptoms within minutes of post- exposure of poisons. They are well absorbed by several other routes like

1) Inhalation

2) Eye exposure

3) Dermatological route

4) Throughout GIT

Dermatological contact is very important, as many cases of toxic symptoms occurs after skin contact alone. The onset of symptoms, severity of disease / symptoms and time duration of OP compound poisoning is estimated by the degree, the route of exposure, the lipid solubility of OP compound and their rate of metabolism and clearence of the particular OP compound and their hepatic activation, required before the activation of OP compounds.

Directly acting OP compound inhibit cholinesterase directly, and does not require bio-activation in the liver. Indirect inhibitors needoxidation by the gastrointestinal tract mucosa and liver to convert indirect inhibitors to its active forms, which finally inhibit cholinesterases. Most of the commonly seen OP poisons like as Malathion and Parathion are indirect OP and need bio-activation before causing its toxic symptoms. The time duration may varies for clinical symptoms to develop it may be from within minute to twenty four hours after exposure of poisons.

Because some OP agents have fat soluble character so they may be stored in the body adipose tissues which act as a "reservoir", and increases its elimination and can finally leads to increase its toxic symptoms. It is commonly seen with OP agents having more lipophilicaffinity like as

1) Fenthion

2) Chlorfenthion

\section{Cholinesterase (Che )}

Cholinesterase is one of the enzyme needed for the proper functioning of the nervous system. It hydrolyses the Ach into choline and acetate. The choline formed is then recycled.

\section{1) A specific acetylcholinesterase or true cholinesterase :-}

Found primarily in nervous tissue and erythrocytes.

\section{2) Non-specific butyrylcholinesterase (BuChE ) or pseudocholinesterase :-}

Present in plasma or serum and non neuronal tissues.

\section{3) Brain cholinesterase}

The pathological effects of organophosphates results from inhibition of cholinesterases ( both RBC and pseudocholinesterase ). These are the markers of exposure, acute toxic effects and reflect actual activity at cholinergic nerve terminal.

In the acute phase of OP agent poisoning it is seen that there is decreased cholinesterase enzyme activity usually within few hours to days and restored to normal level quickly. Genetic variation has been seen in around three percent populations with decreased cholinesterase enzyme activity in serum. Some conditions like liver 
pathology, some physiological state like pregnancy and some inflammatory condition may be acute or chronic can cause variation in serum cholinesterase enzyme level but this variation is not much significant as variation with OP agents

The level and cholinesterase enzyme activity differ from person to person. If there is reduction of cholinesterase enzyme level below 50\% from the normal value it lead to acute cholinergic manifestation of OP agents. This has been noted that cholinesterase level also varies from lab to lab with average $30 \%$ variations.

\section{Pathophysiology of op poisoning :}

OP insecticides act in muscarinic and nicotinic receptors where it decrease acetylcholinesterase enzyme activity by causing accumulation of phosphorylated group to the active site of enzyme which leads to formation of covalent bond and this bond is temporary, this leads to excessive accumulation of acetylcholine (Ach) and leads to cholinergic activation in uncontrolled manner. Over time, one of the two processes occurs. The covalent bond may spontaneously cleaves leaving the enzyme functional again. Meanwhile, the enzyme is prone to "ageing " in its active state in which one of the "R" group may cleave non-enzymatically, leaving a hydroxyl group in its place. Aged acetylcholinesterase enzyme with negatively charged phosphate can no longer be attacked by a negatively charged nucleophile i.e. $\mathrm{OH}$ or an oximate group, and regeneration is no longer possible. Recovery depends upon the time duration for new cholinesterase enzyme formation it may take weeks to recover the functional pathway. This can take upto 3 months for RBC and several weeks for plasma cholinesterase. The time it take for ageing to occur varies according to specific insecticide, but take no longer than 48 hours, clinically, toxic symptoms of OP agents may remain more than a week. Oximes slow down ageing of the phosphorylated cholinesterase and bind to the OPagent, making it non reactive. This results in cholinesterase regeneration and a rise in serum level of cholinesterase.

Clinical manifestations :

\begin{tabular}{|l|l|l|}
\hline $\begin{array}{l}\text { ExcessAch stimulation leads to following } \\
\text { symptoms : PARASYMPATHETIC } \\
\text { SYSTEM }\end{array}$ & C N S & $\begin{array}{l}\text { SKELETAL } \\
\text { MUSCLE }\end{array}$ \\
\hline Low heart rate & Confusion & Muscular weakness \\
\hline Bronchospasm & Excitement & Fasciculation \\
\hline Excessive oral secretion & Seizures & Muscle rigidity \\
\hline Excessive lacrimation & Syncope & Muscle paralysis \\
\hline Vomiting & Apnoea & \\
\hline Abdominal cramping & Vertigo & \\
\hline & & \\
\hline Salivation & Lethargy & \\
\hline Sweating & Hypotension & \\
\hline Pupillary constriction & Hypertension & \\
\hline
\end{tabular}

Triphasic syndrome following op poisoning :

1) Acute phase cholinergic crisis

2) IMS

3) OP induced Delayed polyneuropathy

\section{Acute cholinergic crisis :}

Deposition of acetylcholine in nerve endings as acetylcholinesterase is decreased leading to " cholinergic crisis ", in which there is an initial stimulation and eventual exhaustion of cholinergic synapses. The typical manifestation is of both muscarinic and nicotinic effect i.e parasympathetic activity and acetylcholine accumulation in NM junction respectively and the CNS effect is initial there will be excitation and followed by depression of all CNS activities.

The muscarinic symptoms of cholinergic excess can be remembered as

Dumbbels

Diarrhoea (frequent loose stool )

Urination

Miosis( constricted pupil )

Bronchorrhoea (excessive bronchial secretion more than $100 \mathrm{ml} /$ day )

Bronchospasm

Bradycardia (when the heart rate is less than 60/minute ) 
Emesis (vomiting)

Lacrimation (watering from eyes )

Salivation

Because of nicotinic effect patients usually presents with increased blood pressure and increased heart rate rather than decreased blood pressure and decreased hart rate. In acute phase of OP poisoning due to nicotinic receptors activation causes paralysis of muscles. Fasciculations may be seen, if present signifies OP agent toxicity. In case of severe toxicity of Organophosphate, patients can have confusion, cognitive dysfunction, convulsion, respiratory failure and coma due to central nervous system effects. The effect of paralysis in acute phase of cholinergic crisis usually resolve in 2-3 days but total recovery from paralysis may take upto week after exposure

\section{Intermediate syndrome (ims) :}

Weakness can occur after one to four days of acute phase of cholinergic crisis with or without clinical features and if left untreated can cause respiratory failure.

Intermediate syndrome occurs within 1-4 days after the exposure of poisons and it signifies the long action of acetylcholine in nicotinic receptors. The clinical manifestations are :

1) Extra Ocular muscle weakness leads to ptosis

2) Neck muscle weakness

3) Bulbar muscle weakness

4) Proximal limbs weakness

5) Respiratory muscles weakness leads to dyspnoea

6) Occasional dystonic posturing may be seen

May require mechanical ventilation in an ICU for few days to week.

Intermediate syndrome is due to the inadequate treatment of acute episode specially involving subtherapeutic administration of oximes or inadequate assisted ventilation.

It is proposed that intermediate syndrome may develop as a result of several factors such as

1) The dose and route of exposure

2) The chemical structure of OP compounds

3) The time to initiation of treatment

4) The Possible effort to decrease absorption and increase elimination of organophoshpate compounds.

Once the intermediate syndrome develops it doesn't respond to oxime or atropine therapy. The other causes of respiratory depression in OP poisoning are aspiration of gastric content, increased secretion, inflammatory condition of lungs specially pneumonia, acute respiratory distress syndrome (ARDS ).

The cranial nerve palsies are common. The sensory functions in OP poisoning remain normal and patient become normal in 4-18 days.

The incidence of intermediate syndrome according to several studies has been seen to be $20-68 \%$ and has been usually associated with OPs like

1) Diazinon

2) dimethoate

3) methyl parathion

4) monocrotophos

5) fenthion

6) ethyl parathion

The development of intermediate syndrome might be due to a conformational changes in the ACh receptors altering the depolarization of neuromuscular block to a non-depolarizing block, evidenced by decreased response on tetanic stimulation. 


\section{Delayed syndrome:}

sometimes occurs 1 to 4 weeks after poisoning due to nerve demyelination, and is characterised by flaccid weakness and atrophy of distal limb muscles, or spasticity and ataxia. A mixed sensory-motor neuropathy usually begins in the legs, causing burning or tingling, then weakness.

This syndrome also does not respond to either oximes or atropine. Severe cases progress to complete paralysis, impaired respiration and death. The nerve damage of organophosphate-induced delayed neuropathy is frequently permanent. The mechanism appears to involve phosphorylation of esterases in peripheral nervous tissue and results in a "dying back" pattern of axonal degeneration. Organophosphates that have been associated with delayed neuropathy in humans include chlorophos, chlorpyrifos, dichlorvos, dipterex, ethyl parathion, fenthion, isofenphos, leptophos, malathion, mecarbam, merphos, methamidophos, mipafox, trichlorofon, trichloronate, and TOCP (tri-orthocresyl phosphate).

Parathion ingestion is sometimes associated with haemorrhagic pancreatitis which can terminate fatally. Diazinon has also been implicated. Haemoperfusion is said to be beneficial if this occurs.

Patients poisoned with highly lipid soluble OPs such as fenthion have rarely developed extrapyramidal effects including dystonia, resting tremor, cog-wheel rigidity, and choreoathetosis. These effects began 4 to 40 days after acute OP poisoning and spontaneously resolved over 1 to 4 weeks in survivors.

It is important to note that children may have different predominant signs of organophosphate poisoning than adults. In one study of children poisoned by organophosphate or carbamate compounds, the major signs and symptoms were CNS depression, stupor, flaccidity, dyspnoea, and coma. Other classical signs of organophosphate poisoning such as miosis, fasciculations, bradycardia, excessive salivation and lacrimation, and gastrointestinal symptoms were infrequent.

Bradypnoea sometimes occurs. Respiratory rates of less than 8/minute are not unusual. Snoring prior to fatal overdose has been reported and is likely due to a failure to maintain the patency of the upper airway. Gurgling may occur due to accumulation of pulmonary oedema fluid. Non-cardiogenic pulmonary oedema is an infrequent, but severe, complication of overdose and is generally abrupt in onset (immediate-2 hours). Manifestations include rales, pink frothy sputum, significant hypoxia, and bilateral fluffy infiltrates on chest X-ray. Some patients require mechanical ventilation. Resolution of symptoms usually occurs rapidly with supportive care alone, within hours to 1 to 2 days.

\section{Organophosphate- Induced Delayed Polyneuropathy (Opidpn)}

OPIDPN is a less common clinical condition which occur within a period of one week to 5-6 months of the ingestion of an OP compound, almost exclusively in patients with preceding acute cholinergic toxicity. Organophosphate induced delayed neuropathy is not associated with death but can causes disability because of peripheral muscle weakness, recovery from which is not certain.

The neuropathy in OPIDPN is typically a symmetrical sensorimotor neuropathy with a distal predominance. Initial symptoms are paresthesia in the lower limbs and pain in the calves muscle followed by motor involvement of the lower limbs, manifested by

1) leg weakness

2) foot drop

3) muscle hypotonia

Opidpn is motor predominant, and pure sensory neuropathy do not occurs.

Opidpn might be due to phosphorylation of an enzyme neuropathy target esterase (NTE) in the neurons resulting in neurological dysfunction. This structural changes of neuropathy target esterase causes an irreversible neuropathy. This modified enzyme or phosphorylated enzyme goes for ageing. 


\section{Chronic poisoning:}

It usually occurs as an occupational hazard in agriculturists, especially those who are engaged in pesticide spraying of crops. Route of exposure is usually inhalation or contamination of skin. The following are the main features-

a. Polyneuropathy: paraesthesias, muscle cramps, weakness, gait disorders.

b. CNS Effects : drowsiness, confusion, irritability, anxiety.

c. Sheep Farmer's Disease : psychiatric manifestations encountered in sheep farmers involved in longterm sheep-dip operations.

d. Organophosphate poisoning has been associated with a variety of subacute or delayed onset chronic neurological, neurobehavioural, or psychiatric syndromes. One author has termed these "chronic organophosphate-induced neuropsychiatric disorder; (COPND) and noted that the standard hen neurotoxic esterase test is not sufficient to detect which OPs can cause this condition.

\section{Other important points related to op poisoning :}

The Peradeniya Organophosphorus Poisoning (POP) Scale is predictive of death, necessity for mechanical ventilation, and the required total atropine dose over the first 24 hours. This scale rates 5 clinical variables, each on a 0 to 2 scale: miosis, muscle fasciculations, respirations, bradycardia, and level of consciousness.

Miosis while being a characteristic feature, may not be apparent in the early stages. In fact mydriasis is very often present, and hence treatment should not be delayed if there is absence of pupillary constriction. Blurred vision may persist for several months.

Ocular exposure can result in systemic toxicity. It can cause persistent miosis in spite of appropriate systemic therapy, and may necessitate topical atropine (or scopolamine) instillation.

Exposure to organophosphate vapours rapidly produces symptoms of mucous membrane and upper airway irritation and bronchospasm, followed by systemic symptoms if patients are exposed to significant concentrations. While respiratory failure is the commonest cause of death, other causes may contribute including hypoxia due to seizures, hyperthermia, renal failure, and hepatic failure.

Patients with OP poisoning and QTc prolongation are more likely to develop respiratory failure and have a worse prognosis than patients with normal QTc intervals. Patients with OP poisoning who develop PVCs (premature ventricular contractions) are more likely to develop respiratory failure and have a higher mortality rate than patients without PVCs.

Aspiration of preparations containing hydrocarbon solvents may cause potentially fatal lipoid pneumonitis.

\begin{tabular}{|c|c|}
\hline $\begin{array}{l}\text { TYPE OF } \\
\text { POISONTNG }\end{array}$ & CENVICAX MENTFESTATXONS \\
\hline LATENT & $\begin{array}{l}\text { Nil dintcal symptoms. diagnosis depends on the } \\
\text { cholinesterase acuvity which is decreased by } 50 \%\end{array}$ \\
\hline MIID & $\begin{array}{l}\text { The patient is able to walk but can present with symptoms of } \\
\text { fatigue. head ache. vertigo. numbness of limbs. emesis. } \\
\text { increased perspiration, tightness of chest, abdominal pain or } \\
\text { loose stool; cholinesterase activity is } 20-50 \% \text {. }\end{array}$ \\
\hline MODERATE & $\begin{array}{l}\text { The patient is not able to walk and difficulty in using both } \\
\text { limbs, speaking and swallowing difreulty signifies bulbax } \\
\text { palsy, musculax faseieulation, constrieted pupils, with in the } \\
\text { severity of the elinical features deveribed above; eholinesterave } \\
\text { activity is } 10-20 \% \text {. }\end{array}$ \\
\hline SEVERE & $\begin{array}{l}\text { Comatous mariced pupillary constriction, loss of pupil reflex } \\
\text { to light, muscular fasciculation, paralysis. excessive secretion, } \\
\text { basal crepts in the lungs field, dyspnoea cyanosis and } \\
\text { respiratory failure; cholinesterase activity is less than } 10 \% \text {. }\end{array}$ \\
\hline
\end{tabular}




\section{Serum lipase:}

Majority of lipase secretion in human body is pancreas gland. It has a catalytic activity for fatty acid which is the very important step in the food metabolism. long chain Fatty acid contain glycerol esters which is catalyzed by pancreatic lipase enzyme to form medium or small chain fatty acid and glycerol. And their catalytic activity is accompanied by bile salt and colipase and the secretions of colipase is in equal quantity. Different form of lipase activities like,

1) Phospholipases 2) Sphingomyelinases

Some organisms during their infectious stage produces lipase especially candida albicans produces variety of lipase

\section{Structure and catalytic mechanism:}

Although a diverse array of genetically distinct lipase enzymes are found in nature, and represent several types of protein folds and catalytic mechanisms, most are built on an alpha/beta hydrolase fold and employ a chymotrypsin like hydrolysis mechanism using a catalytic triad consisting of

1) Serine nucleophil

2) A histidine base

3) Acid residue ( usually aspartic acid )

\section{Physiological distribution:}

Lipases are responsible for various biochemical processes like routine metabolism of food containing TGL to cell signaling and inflammation. So lipase activity are divided as per their function like intracellular or extracellular functions. For example some lipase are specifically alied to cell organelle called as lysosome.

For the dietary lipid, pancreatic lipase is responsible for its metabolism into simpler form for their better absorption and utilization by the body.

Pathogenic organisms also producs lipases for absorption and its utilization.

Cell wall and cell membrane are the important part of living cell of the body and mainly formed by lipid in which lipases have main role for the integrity if cell membrane.

How dandruff happens in our body, a fungus called as malasezia utilizes lipase and convert sebum to oleic acid which causes increased cell proliferation and finally dandruff.

\section{Human lipases :}

Pancreatic gland plays a major role in the production of pancreatic lipase.

Elevated lipase level indicates

1) Acute pancreatitis

2) Chronic pancreatitis

3) Gall stone

4) Bowel obstruction

5) Celiac disease

6) Gastroenteritis

7) An ulcer

8) Pancreatic cancer

9) Crohn disease

Decreased lipase enzyme level may indicate the presence of cystic fibrosis.

\section{Diagnosis :}

1. Depression of cholinesterase activity:

a. If the RBC cholinesterase level is less than $50 \%$ of normal, it indicates organophosphate toxicity. RBC cholinesterase levels are more reliable in diagnosing organophosphate poisoning than serum cholinesterase. 


\section{- Disadvantages-}

- Normal cholinesterase level is based on population estimates and there is a wide distribution in the definition of normal. A person with a "high normal" level may become symptomatic with a "low normal" activity.

- A very low cholinesterase level does not always correlate with clinical illness.

- False depression of RBC cholinesterase level is seen in pernicious anaemia, haemoglobinopathies, antimalarial treatment, and blood collected in oxalate tubes. Elevated levels may be seen with reticulocytosis due to anaemias, haemorrhage, or treatment of megaloblastic or pernicious anaemias.

b. Depression of plasma cholinesterase level (to less than 50\%) is a less reliable indicator of organophosphate toxicity, but is easier to assay and more commonly done. Depressions in excess of $90 \%$ may occur in severe poisonings, and is usually associated with mortality.

-Because it is a liver protein, plasma cholinesterase activity is depressed in cirrhosis, neoplasia, malnutrition, and infections, some anaemias, myocardial infarction, and chronic debilitating conditions.

- Certain drugs such as sucinyl choline, lignocaine, codeine, and morphine, thiamine, ether, and chloroquine can also depress its activity.

- Studies have demonstrated that RBC cholinesterase levels may be significantly higher in pregnant women than in nonpregnant controls, while plasma cholinesterase levels are generally lower during pregnancy. These levels revert to normal by six weeks postpartum.

- The organophosphates phosdrin and chlorpyrifos may selectively inhibit plasma pseudocholinesterase, while phosmet and dimethoate may selectively inhibit red blood cell cholinesterase

c. For the purpose of estimation of cholinesterase level, blood should be collected only in heparinised tubes. Alternatively, samples can be frozen. Plasma cholinesterase usually recovers in a few days or weeks; red blood cell cholinesterase recovers in several days to 4 months depending on severity of depression.

2. P-Nitrophenol Test: P-nitrophenol is a metabolite of some organophosphates (e.g. parathion, ethion), and is excreted in the urine. Steam distill $10 \mathrm{ml}$ of urine and collect the distillate. Add sodium hydroxide (2 pellets)

and heat on a water bath for 10 minutes. Production of yellow colour indicates the presence of $\mathrm{p}$ nitrophenol. The test can also be done on vomitus or stomach contents.

3. Thin Layer Chromatography (TLC): The presence of an organophosphate in a lavage, or vomit, or gastric aspirate sample can also be determined by TLC. The sample is extracted twice with $5 \mathrm{ml}$ of petroleum ether, and the extract is washed with distilled water. It is then dried in steam compressed air, reconstituted in methanol, and spotted on silica gel-coated TLC plate along with the standard and run in a mixture of petroleum ether and methanol $(25: 1)$. After the solvent has travelled a considerable distance, the plate is dried and exposed to iodine vapour. The RF is compared with that of the standard.

\section{Ultrasonography of abdomen :}

This imaging is used to confirm whether the pancreas

1) normal

2) acute pancreatitis changes

3) chronic pancreatitis changes

\section{Anatomy of pancreas :}

Retroperitoneal, over the spine placed transverse In the region posterior to stomach $80 \mathrm{gm}, 15-20 \mathrm{~cm}$ Splenic vein posterior to pancreas

\section{Finding :}

In USG Abdomen, the pancreas is hyperechoic, becoming increasingly so in the elderly, in small children ,it is less echoeic than livermain pancreatic duct normally can be visualized and is $2 \mathrm{~mm}$ or less. 
Identified by particularly splenic vein, which lies posterior to pancreas, and sup. Mesentric artery, which is seen as a ring like a bright echogenic wall No capsule so margin of pancreas is ill defined. Acute inflammation causes the pancreatic tissue to become necrosed.

In more severe cases the pancreas is enlarged and hypoechoic due to edema. The main duct may be dilated or prominent. As the condition progresses, digestive enzymes leak out, forming collections or pseudocysts. These are most frequently found in the lesser sac, near the tail of the pancreas, but can occur anywhere in abdomen

\section{Chronic pancreatitis changes :}

The normal pancreatic tissue is progressively replaced by fibrosis.

The pancreas becomes abnormally hyperechoic.

Irregular dilatation of pancreatic duct

Pseudocyst seen in $25 \%$ cases

Calcification may be identified in the pancreatic tissue.

treatment :

Determine plasma or red blood cell cholinesterase activities. Depression in excess of 50 per cent of baseline is generally associated with severe symptoms.

\section{Acute Poisoning:}

a. Decontamination:

- If skin spillage has occurred, it is imperative that the patient be stripped and washed thoroughly with soap and water.

- Shower is preferable. Make the patient stand (if he is able to) under the shower, or seated in a chair.

- Wash with cold water for 5 minutes from head to toe using non-germicidal soap. Rinse hair well.

- Repeat the wash and rinse procedure with warm water.

- Repeat the wash and rinse procedure with hot water.

- Treating personnel should protect themselves with water-impermeable gowns, masks with eye shields, and shoe covers. Latex and vinyl gloves provide inadequate protection, unless a double pair is used.

- If ocular exposure has occurred, copious eye irrigation should be done with normal saline or Ringer's solution. If these are not immediately available, tap water can be used.

- In the case of ingestion, stomach wash can be done, though this is often unnecessary because the patient would have usually vomited several times by the time he is brought to hospital. Activated charcoal can be administered in the usual way.

\section{b.Antidotes:}

- Atropine-It is a competitive antagonist of acetylcholine at the muscarinic postsynaptic membrane and in the CNS, and blocks the muscarinic manifestations of organophosphate poisoning.

- Oximes-The commonest is pralidoxime (pyridine2-aldoxime methiodide), which is a nucleophilic oxime that helps to regenerate acetylcholinesterase at muscarinic, nicotinic, and CNS sites. Actually, human studies have not conclusively substantiated the benefit of oxime therapy in acute organophosphate poisoning, but they are widely used. Most authors advocate the continued use of pralidoxime in the clinical setting of severe organophosphate poisoning.

\section{Supportive Measures:}

- Administer IV fluids to replace losses.

- Maintain airway patency and oxygenation. Suction secretions. Endotracheal intubation and mechanical ventilation may be necessary. Monitor pulse oximetry or arterial blood gases to determine need for supplemental oxygen.

- Oxygenation/intubation/positive pressure ventilation: To minimise barotrauma and other complications, use the lowest amount of PEEP possible while maintaining adequate oxygenation. Use of smaller tidal 
volumes $(6 \mathrm{ml} / \mathrm{kg})$ and lower plateau pressures (30 $\mathrm{cm}$ water or less) has been associated with decreased mortality and more rapid weaning from mechanical ventilation in patients with ARDS.

- The following drugs are contraindicated: parasympathomimetics, phenothiazines, antihistamines, and opiates. Do not administer succinylcholine (suxamethonium) or other cholinergic medications. Prolonged neuromuscular blockade may result when succinylcholine is administered after organophosphate exposure.

- Treat convulsions with benzodiazepines or barbiturates.

- Antibiotics are indicated only when there is evidence of infection.

- Haemoperfusion, haemodialysis, and exchange transfusion have not been shown to affect outcome or duration of toxicity in controlled trials of organophosphate poisoning.

\section{d. Prevention of Further Exposure:}

After the patient has recovered, he should not be re-exposed to organophosphates for at least a few weeks since he is likely to suffer serious harm from a dose that normally would be harmless, owing to alteration of body chemistry. Following acute poisoning, patients should be precluded from further organophosphate exposure until sequential RBC cholinesterase (AChE) levels have been obtained and confirm that AChE activity has reached a plateau. Plateau has been obtained when sequential determinations differ by no more than 10\%. This may take 3 to 4 months following severe poisoning.

\section{E. Treatment of Pregnant Victim:}

Therapeutic choices during pregnancy depend upon specific circumstances such as stage of gestation, severity of poisoning, and clinical signs of mother and foetus. The mother must be treated adequately to treat the foetus. A severely poisoned patient with a late gestation viable foetus may be a candidate for emergency Caesarean section. The foetus may require intensive care after birth.

- Pralidoxime chloride is recommended for use in the pregnant patient to counteract muscle weakness.

- Glycopyrrolate: Unlike atropine, glycopyrrolate usually does not readily cross the placenta and would not directly affect foetal poisoning. However, the

foetus may be best served by treating the mother to retain good respiratory function and foetal oxygenation.

\section{Chronic Poisoning:}

a. Removal of the patient from the source of exposure.

b. Supportive and symptomatic measures.

\section{Antidotes for Organophosphates Atropine}

Mode of action: Blocks the muscarinic manifestations of organophosphates. However, since atropine affects only the postsynaptic muscarinic receptors, it has no effect on muscle weakness or paralysis

Diagnostic dose: Organophosphate-poisoned patients are generally tolerant to the toxic effects of atropine (dry mouth, rapid pulse, dilated pupils, etc.)

If these findings occur following a diagnostic atropine dose, the patient is probably not seriously poisoned Diagnostic dose-Adult: $1 \mathrm{mg}$ intravenously or intramuscularly; Child $-0.25 \mathrm{mg}$ (about $0.01 \mathrm{mg} / \mathrm{kg}$ ) intravenously or intramuscularly

Therapeutic dose: 1 to $2 \mathrm{mg}$ IV or IM (adult); $0.05 \mathrm{mg} / \mathrm{kg}$ IV (child); every 15 minutes until the endpoint is reached, i.e. drying up of tracheobronchial secretions. Pupillary dilatation and tachycardia are not reliable indicators of the endpoint 
Atropine can also be administered as an IV infusion after the initial bolus dose, at a rate of 0.02 to 0.08 $\mathrm{mg} / \mathrm{kg} / \mathrm{hr}$. Once the endpoint has been reached, the dose should be adjusted to maintain the effect for at least 24 hours

Atropinisation must be maintained until all of the absorbed organophosphate has been metabolised. This may require administration of 2 to 2,000 milligrams of atropine over several hours to weeks

Atropine therapy must be withdrawn slowly to prevent recurrence or rebounding of symptoms, often in the form of pulmonary oedema. This is especially true of poisonings from lipophilic organophosphates such as fenthion

\section{Pralidoxime (Pyridine-2-aldoxime methiodide; 2-PAM)}

Structurally, pralidoxime is 2-hydroxyiminomethyl-1-methyl pyridinium chloride

Mode of action: It is usually given along with atropine. Pralidoxime competes for the phosphate moiety of the organophosphorus compound and releases it from the acetylcholinesterase enzyme, thereby liberating the latter and reactivating it While it is advisable to begin pralidoxime therapy within 48 hours of poisoning, it can be administered even much later with beneficial effects Till recently, pralidoxime was said to be contraindicated in carbamate poisoning because experiments with carbaryl (Sevin) suggested a worsening of symptoms when it was administered. However, recent studies have pointed out that while pralidoxime is not a necessary adjunct to atropine in carbamate overdose, it may be beneficial in some cases

Dose: For adults - 1 to 2 gm in 100 to $150 \mathrm{ml}$ of $0.9 \%$ sodium chloride, given IV over 30 minutes This can be repeated after 1 hour, and subsequently every 6 to 12 hours, for 24 to 48 hours Contd Alternatively, a $2.5 \%$ concentration of pralidoxime can be given as a loading dose followed by a maintenance dose

Serious intoxication may require continuous infusion of $500 \mathrm{mg} / \mathrm{hr}$ in adults. Many workers feel that this high dose therapy minimises the incidence of complications such as the Intermediate Syndrome

Maximum dose should not exceed $12 \mathrm{gm}$ in a 24 hour period. Infusion over a period of several days may be necessary and is generally well tolerated

The WHO currently recommends an initial bolus of at least $30 \mathrm{mg} / \mathrm{kg}$, followed by an infusion of more than $8 \mathrm{mg} / \mathrm{kg} / \mathrm{hr}$

It is estimated that a plasma concentration of at least $4 \mathrm{mg} / \mathrm{L}$ may be necessary for pralidoxime to be effective

For children-20 to $40 \mathrm{mg} / \mathrm{kg}$ to a maximum of $1 \mathrm{gm} /$ dose given IV, and repeated every 6 to 12 hours for 24 to 48 hours

Alternatively, iv infusion can be resorted to, at a rate of 9 to $19 \mathrm{mg} / \mathrm{kg} / \mathrm{hr}$

Adverse effects: Rapid administration can cause tachycardia, laryngospasm, and even cardiac or respiratory arrest

Other adverse effects include drowsiness, vertigo, headache, and muscle weakness

It is generally not advised for the treatment of carbamate overdose, especially carbaryl

In cases where intravenous administration is not possible, pralidoxime can be given intramuscularly as an initial dose of 1 gram or up to 2 grams in cases of very severe poisoning In some countries obidoxime is used instead of pralidoxime, though it does not appear to be superior to the latter It is apparently favoured over pralidoxime in clinical practice in Belgium, Israel, The Netherlands, Scandinavia, and Germany, and is the only oxime available in Portugal

A few investigators suggest that oximes have only a limited role in organophosphate poisoning, and successful management is possible without employing them at all, though this view is not shared by most other workers in the field 


\section{Diazepam}

Some studies indicate that the addition of diazepam to atropine and 2-PAM improves survival. It reduces the risk of seizure-induced brain and cardiac damage

Dose: For adults - 5 to $10 \mathrm{mg}$ IV slowly, every 15 minutes, upto a maximum of $30 \mathrm{mg}$

For children -0.25 to $0.4 \mathrm{mg} / \mathrm{kg}$ IV slowly, every 5 to 10 minutes, upto a maximum of $10 \mathrm{mg}$

If diazepam is ineffective, phenytoin or phenobarbitone can be used instead

\section{Effect of organophosphorus compound on pancreas :}

Various studies have shown that there is increased incidence of Pancreatitis and its complications after ogganophosphate intoxication when compared to general population. There is elevated serum amylase and lipase level in patients.

Though the exact mechanism of pancreatitis in OP intoxication in not known, the following mechanism have been suggested

1) OP insecticides increases the intraductal pressure and exocrine pancreatic flow. The increase in pressure leads to extravasation of pancreatic fluid. This increased pancreatic exocrine flow could be due to direct cholinergic hyperstimulation of pancreatic acinar and ductal cell.

2) Experimental data supports the view that these OP compounds causes a functional ductal obstruction at the same time as stimulation of pancreatic exocrine secretion.

3) There is pancreatic interstitial edema, acinar cell vacuolization, hyperamylasemia and hyperlipasemia following OP intoxication.

\section{Materials And Methods}

Subjects : Patients who consumed organophosphate poisons.

Study design : A prospective cross sectional study.

Ethical committee approval : The ethical committee approval was obtained to carry out study in hospital.

Study setting : Government Rajaji Hospital Madurai

Duration of study : Feb2015 to July 2015

Materials : This study is to be conducted among 100 patients who are admitted in Govt. Rajaji hospital, Madurai with history and clinical features of organophosphate poisoning.

\section{Study criteria :}

\section{Inclusion criteria :}

1) Age $>12$ years, both sex

2) History of exposure to organophosphate compounds presenting with characteristic clinical manifestations of organophosphate poisoning.

\section{Exclusion criteria :}

1) Alcoholic patient

2) Pre-existing pancreatic disease

3) Mixed poisoning with other substances

4) Gone through ERCP in previous 24 hour

5) h/0 suggestive of parotid gland disease

6) lipid disorder

7) hepatic and renal disease

8) h/o drug intake like

\section{azathioprine}

\section{6-Mercaptopurine}

Thiazides

Frusemide

Pentamidine 


\section{Study protocol :}

Patient admitted in GRH were the study group. A previously designed proforma was used to collect the demographic and clinical details of patients.

\section{Collaborating department :}

1) Department of biochemistry, Madurai medical college, Madurai

2) Department of radiology, Madurai medical college, madurai

\section{Exposure assessment :}

The following parameters were seen for association with OP pesticides exposure -

- Demography

Age

Sex

Admission time

Socioeconomic status

Family status

Reason for consumption

- Poison particulars

Severity grade

Symptoms after taking poisons

Immediate steps taken after OP consumption

- Biochemical evaluation which includes

Serum amylase level

Serum lipase level

- Clinical features

Pupil size, pulse rate, blood pressure, respiratory rate, secretions

\section{Sample collection :}

1) 100 patients satisfying the inclusion criteria will be selected for the study.

2) About $3 \mathrm{ml}$ of venous will be collected in two occasions from the each subject within 24 hours of consumption of OP poison (sample 1) and next after 24 hours of first sample (sample 2)

3) Serum will be separated and Serum amylase will be estimated

4) if serum amylase level significantly elevated (3-4 times than normal ) than serum lipase

5) If serum lipase level significantly elevated ( 3 times than normal )than to confirm the diagnosis usg abdomen

\section{Observation and results}

\section{A. Characteristics of cases studied:}

Table 1: Age distrib

\begin{tabular}{|l|l|l|}
\hline Age distribution & No.01 enses & Dead \\
\hline-25 & 8 & 0 \\
\hline $26-40$ & 37 & 2 \\
\hline $41-55$ & 45 & 3 \\
\hline $56-70$ & 10 & 1 \\
\hline Total & 100 & 6 \\
\hline & & 0.856 \\
& & NS \\
\hline
\end{tabular}




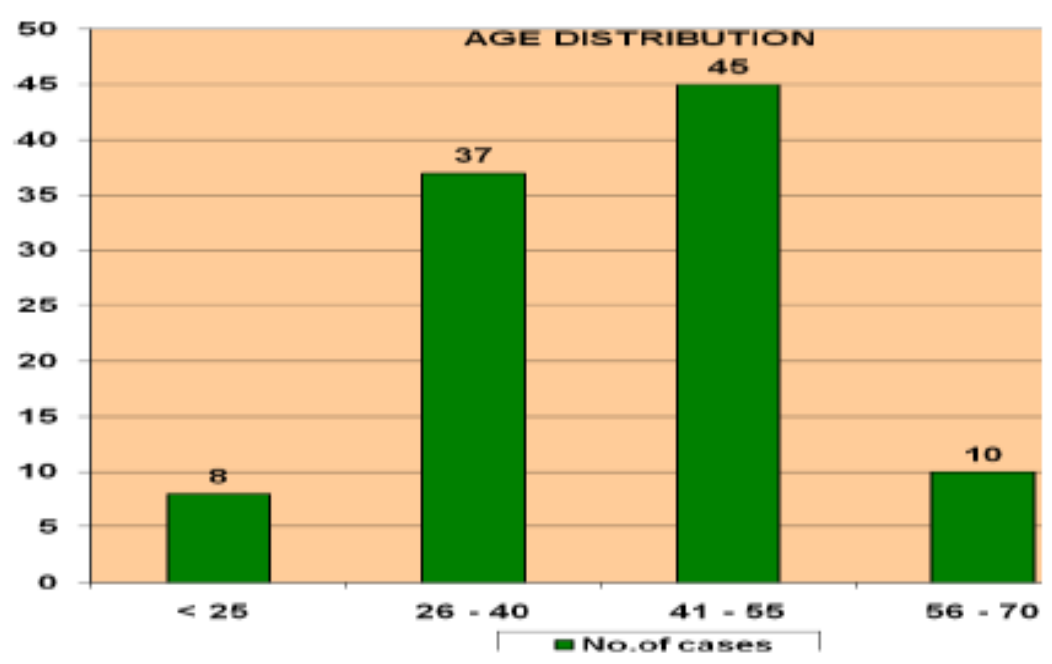

Table 2 : Sex distribution

\begin{tabular}{|l|l|l|}
\hline Gender & Cases & Dead \\
\hline Male & 75 & 5 \\
\hline Female & 25 & 1 \\
\hline & & 0.978 NS \\
\hline
\end{tabular}

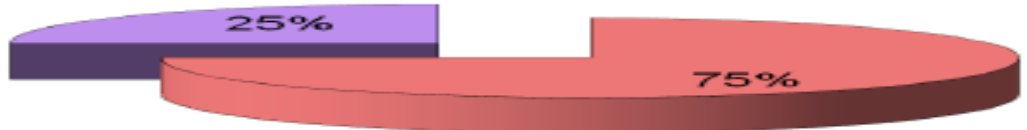

DMale DFemale

Table 3: Hematological Parameter

Amylase level - I

\begin{tabular}{|c|c|c|}
\hline & \multicolumn{2}{|c|}{ Amylase level - I } \\
\hline $\begin{array}{l}\text { Age } \\
\text { distribution }\end{array}$ & Mean & SD \\
\hline $12-25$ & 141.8 & 123.5 \\
\hline $\begin{array}{l}26-40 \\
(37)\end{array}$ & 180.7 & 1578 \\
\hline $\begin{array}{l}41-55 \\
(45)\end{array}$ & 217.6 & $1 \leq 0.1$ \\
\hline $\begin{array}{l}50-70 \\
(10)\end{array}$ & 220.3 & 175.4 \\
\hline
\end{tabular}


Amylase Level - Ii

\begin{tabular}{|l|l|l|}
\hline \multicolumn{2}{|l|}{ Amylase 1eve1 - II } \\
\hline $\begin{array}{l}\text { Age } \\
\text { distribution }\end{array}$ & Mean & SD \\
\hline $12-25$ & 100.6 & 99.7 \\
\hline $26-40(37)$ & 90.5 & 85.2 \\
\hline $41-55(45)$ & 111 & 92 \\
\hline $56-70(10)$ & 138.7 & 118.6 \\
\hline
\end{tabular}

Reason for poisoning

\begin{tabular}{|l|l|}
\hline Reason & cases \\
\hline Financial problem & 23 \\
\hline Familial stress & 77 \\
\hline
\end{tabular}

Reason For Poisoning
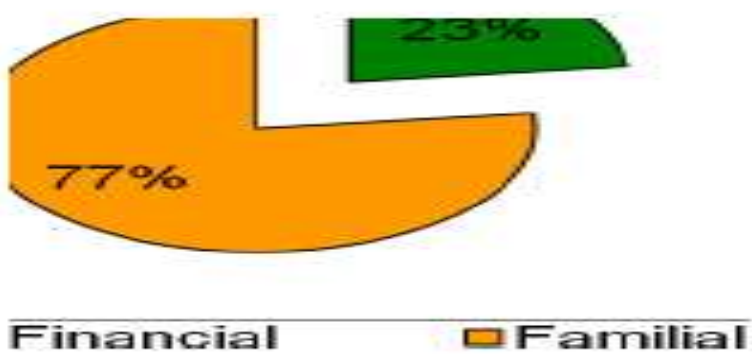

Mode of Consumption

\begin{tabular}{|l|l|l|}
\hline Mode of & Dead \\
\hline Alone & cases & 1 \\
\hline Oruers & 28 & 0 \\
\hline Water & 3 & 5 \\
\hline & 00 & 6 \\
\hline
\end{tabular}

Mode of Consumption






\section{Agents}

\begin{tabular}{|l|l|}
\hline Agents & cases \\
\hline Bug killer liquid & 22 \\
\hline Chlorpyrifos & 12 \\
\hline Dichlorofos & 7 \\
\hline Fenthion & 3 \\
\hline Monocrotophos & 13 \\
\hline Methyl parathion & 30 \\
\hline Quinolphos & 13 \\
\hline
\end{tabular}



\section{Clinical Features}

Secretions :

\begin{tabular}{|l|l|}
\hline CF - S & Cases \\
\hline+ & 3 \\
\hline++ & 87 \\
\hline+++ & 7 \\
\hline Ni1 & 3 \\
\hline Total & 100 \\
\hline
\end{tabular}


“A Study On Serum Amylase Level And Prevalence Of Acute Pancreatitis In .....

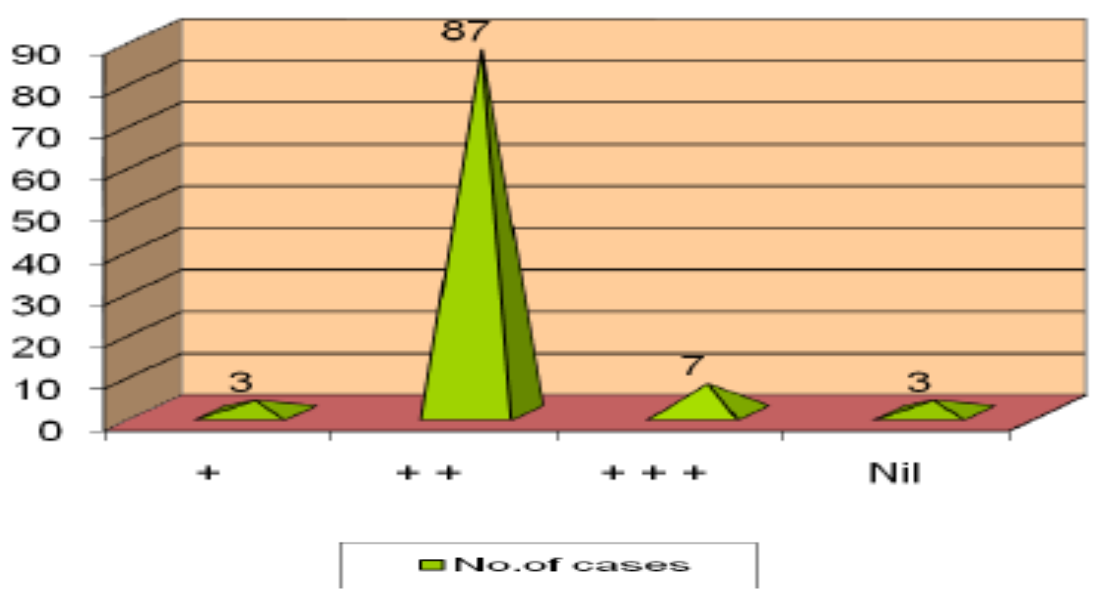

\begin{tabular}{|c|c|}
\hline & \\
\hline Mental status & cases \\
\hline+ & 17 \\
\hline++ & 1 \\
\hline Ni1 & $\mathbf{8 2}$ \\
\hline
\end{tabular}

- PIN POINTT PUPIL

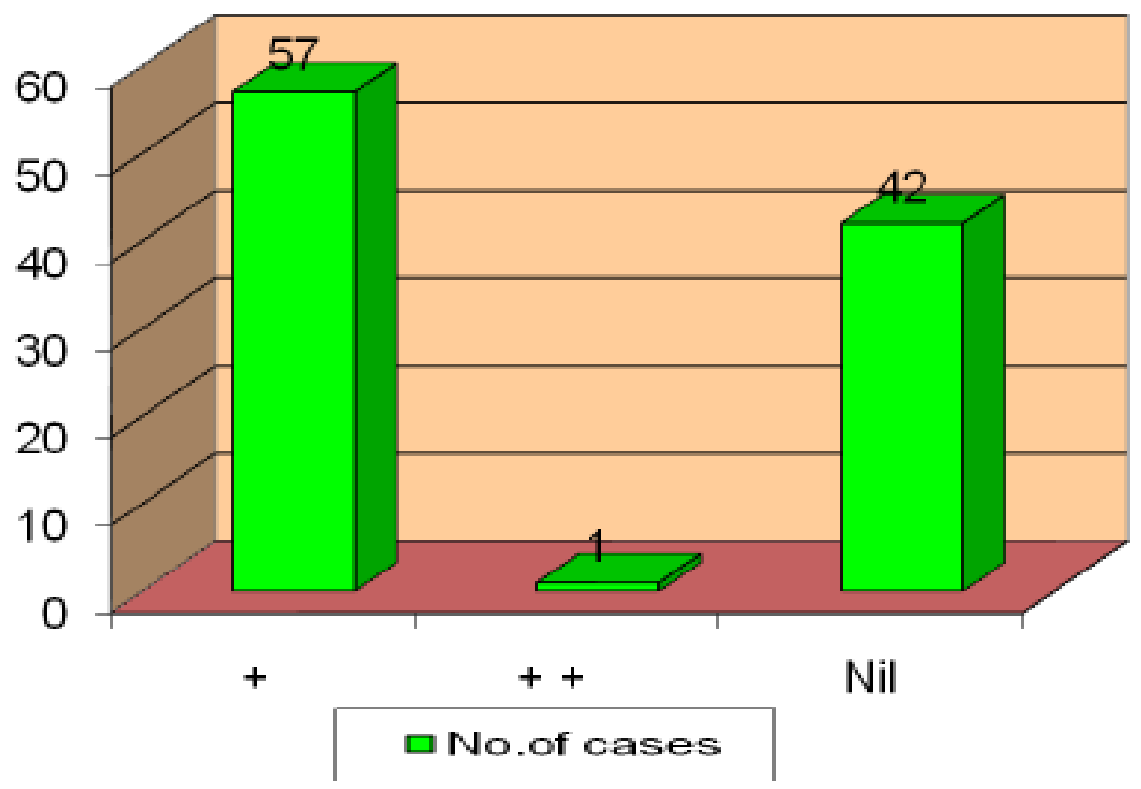


Faseicutarton t

\begin{tabular}{|c|c|}
\hline Tasciculation & No. of cases \\
\hline+ & 14 \\
\hline Nis & 86 \\
\hline
\end{tabular}

FASICULATION

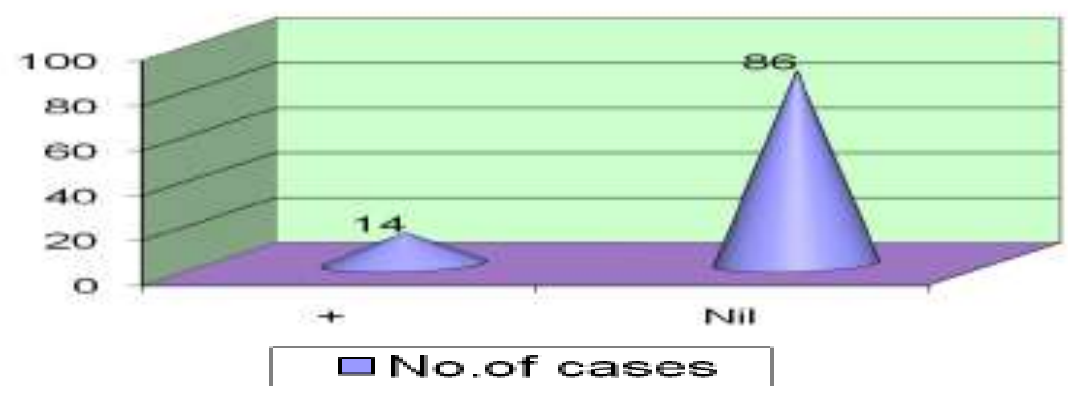

\begin{tabular}{|c|c|}
\hline Heart Rate & No-OEcases \\
\hline BFADYCAFIIA & 42 \\
\hline NOFMAI & 58 \\
\hline
\end{tabular}

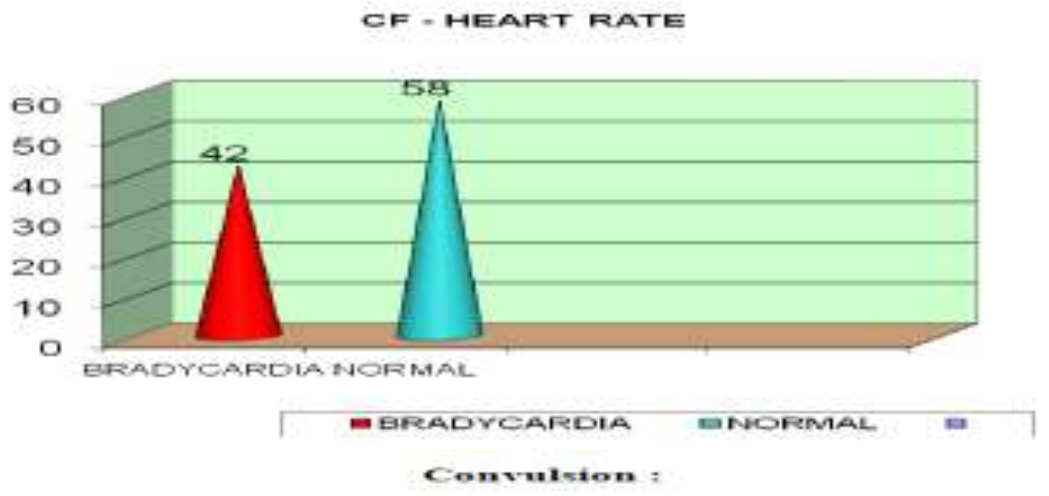

\begin{tabular}{|c|c|}
\hline $\mathrm{CH}-\mathrm{c}$ & No.0t cases \\
\hline+ & 12 \\
\hline Win & 88 \\
\hline
\end{tabular}

$C F-C$






\section{Respiratory failure :}

\begin{tabular}{|l|l|}
\hline & \\
\hline Respiratory failure & No. of cases \\
\hline+ & 21 \\
\hline Nil & 79 \\
\hline
\end{tabular}

CF - RESPIRATORY FAILURE
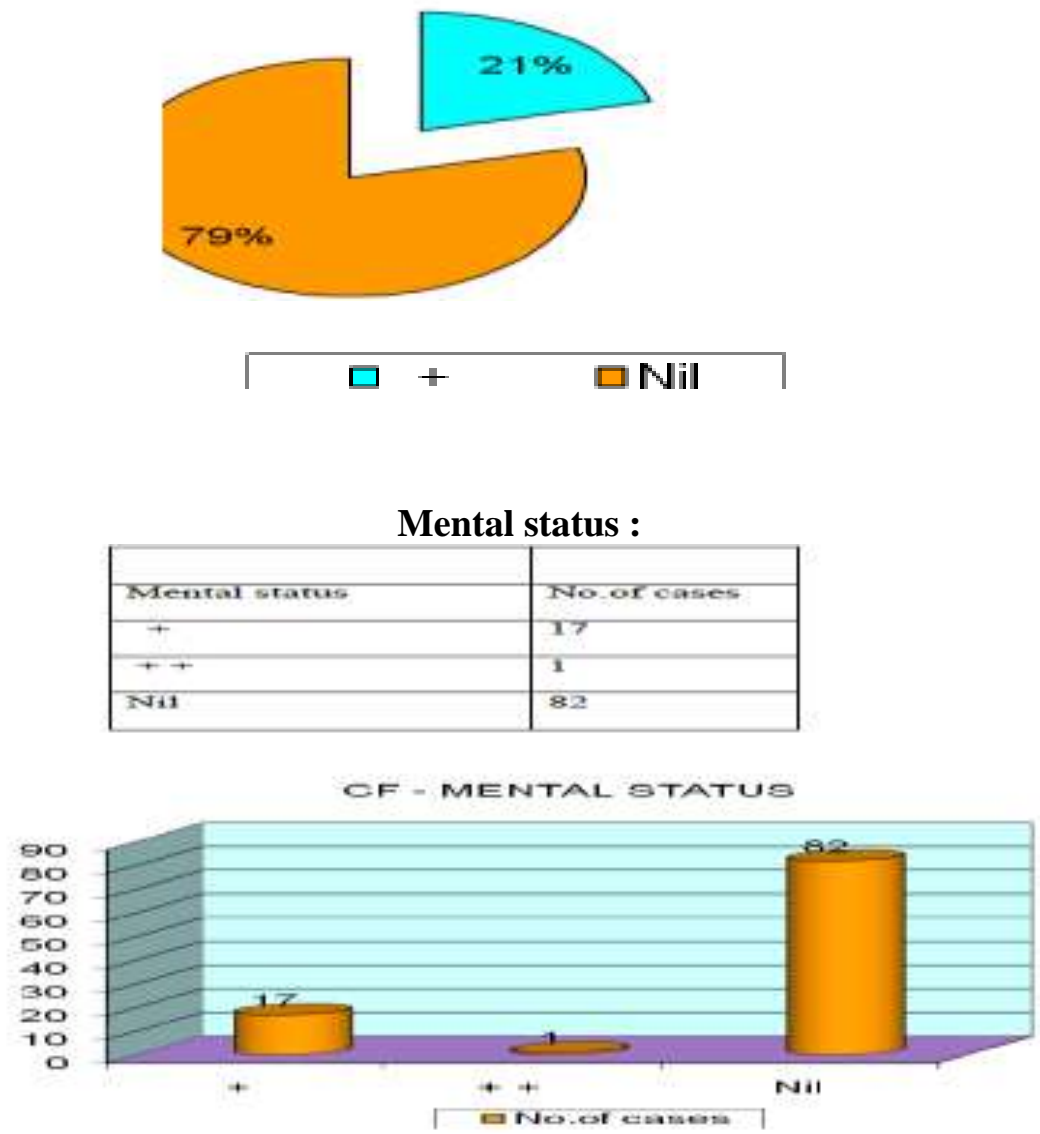

Age and amylase level :I

\begin{tabular}{|l|l|l|}
\hline & \multicolumn{2}{|l|}{} \\
\hline & \multicolumn{2}{|l|}{ Amylase leve1 - I } \\
\hline Age distribution & Mean & SD \\
\hline $12-25$ & 141.8 & 123.5 \\
\hline $26-40(37)$ & 189.7 & 157.8 \\
\hline $41-55(45)$ & 217.6 & 150.1 \\
\hline $56-70(10)$ & 220.3 & 175.4 \\
\hline
\end{tabular}


AOE VSAMYLASE LEVEL I

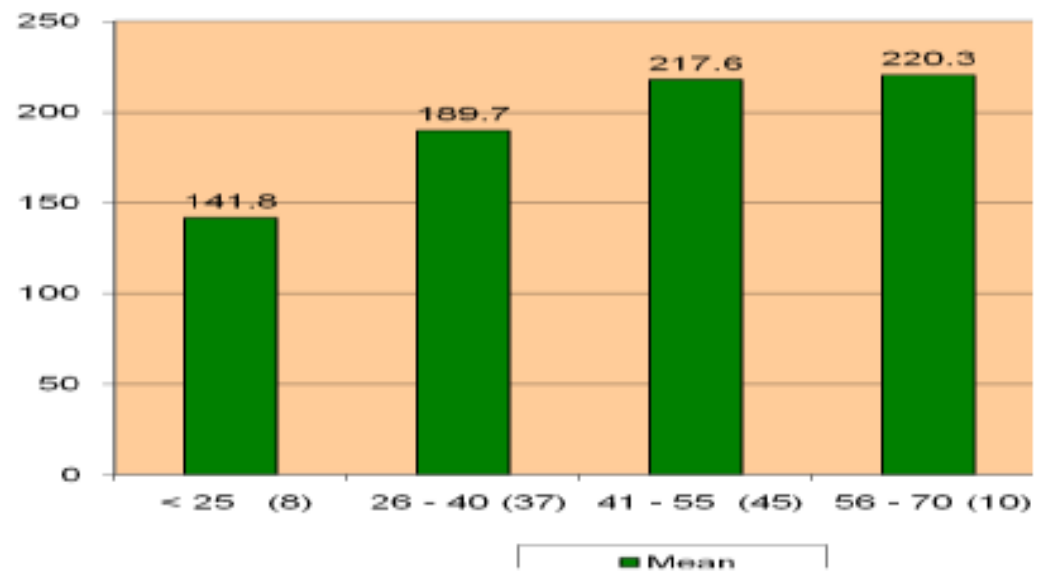

Age and amylase level - II

\begin{tabular}{|c|c|c|}
\hline & \multicolumn{2}{|c|}{ Amylase level - II } \\
\hline Age distribution & Mean & SD \\
\hline$<25(8)$ & 100.6 & 99.7 \\
\hline $26-40(37)$ & 99.5 & 85.2 \\
\hline $41-55(45)$ & 111 & 92 \\
\hline $56-70(10)$ & 138.7 & 118.6 \\
\hline
\end{tabular}

AGE VS AMYLASE LEVEL II



Sex and amylase level : I 
“A Study On Serum Amylase Level And Prevalence Of Acute Pancreatitis In .....

\begin{tabular}{|l|l|l|}
\hline & \multicolumn{2}{|l|}{ Amylase level - I } \\
\hline Sex & Mean & SD \\
\hline Male & 191.7 & 148.8 \\
\hline Female & 230.7 & 164.8 \\
\hline
\end{tabular}



Sex and amylase level -II

\begin{tabular}{|c|c|c|}
\hline & \multicolumn{2}{|c|}{ Amylase level-II } \\
\hline Sex & Mean & SD \\
\hline Male & 100.7 & 87.6 \\
\hline Female & 132.5 & 103.3 \\
\hline & $0.136 \mathrm{NS}$ & \\
\hline
\end{tabular}

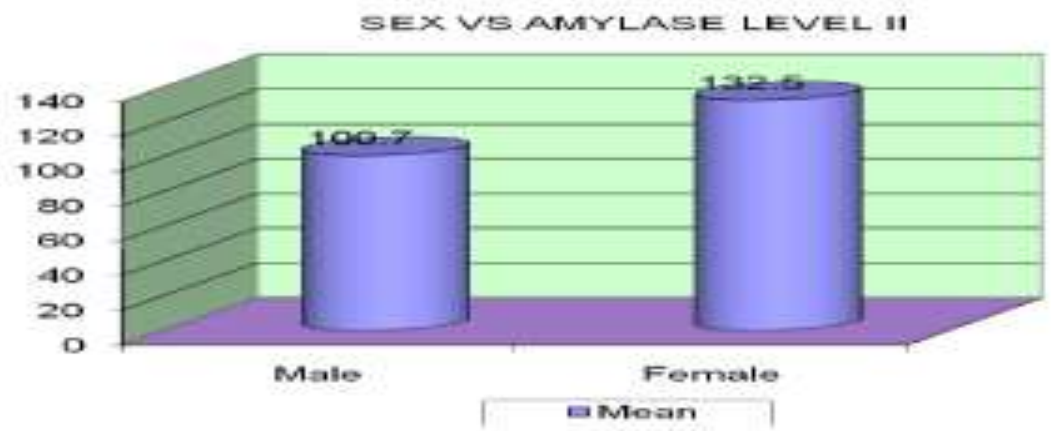

Comparision Of Amylase Level I And Ii For Pinpoint

\begin{tabular}{|c|l|l|l|l|}
\hline \multirow{2}{*}{ Pinpoint pupil } & \multicolumn{2}{|l|}{ Amylase level I } & \multicolumn{2}{l|}{ Amylase leve1 II } \\
\cline { 2 - 5 } & Mean & SD & Mean & SD \\
\hline Present (58) & 244.9 & 152.9 & 141.6 & 108 \\
\hline Absent (42) & 141.5 & 133.1 & 63.2 & 26.2 \\
\hline & & & & \\
\hline & $<0.001$ Significant & $<0.001$ Significant \\
\hline
\end{tabular}


“A Study On Serum Amylase Level And Prevalence Of Acute Pancreatitis In .....

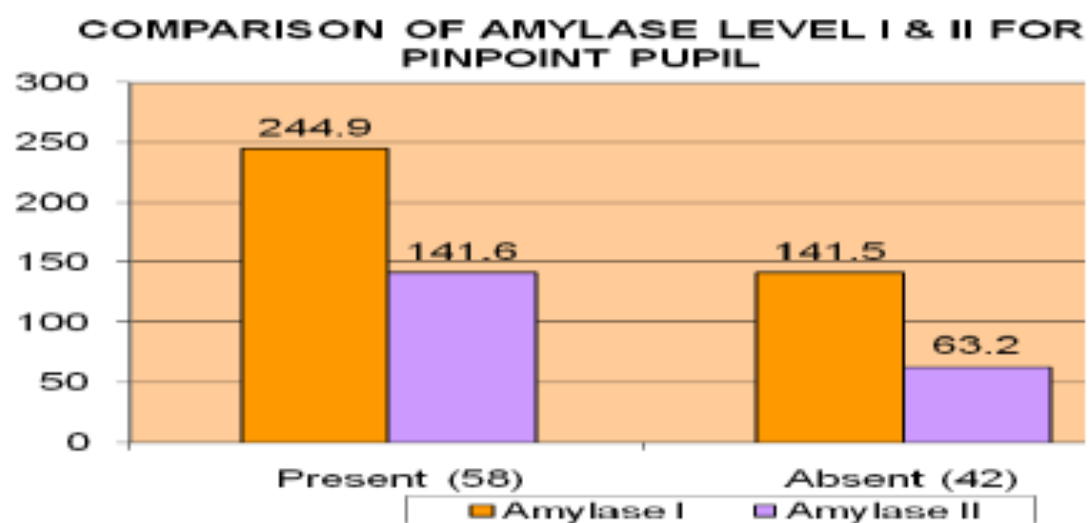

Comparision Of Amylase Level I And Ii For Mental Status

\begin{tabular}{|l|l|l|l|l|}
\hline & & & & \\
\hline \multirow{2}{*}{ Mental status } & \multicolumn{2}{|l|}{ Amylase level I } & \multicolumn{2}{l|}{ Amylase level II } \\
\cline { 2 - 5 } & Mean & SD & Mean & SD \\
\hline Present (18) & 374.2 & 78.8 & 264.2 & 74.3 \\
\hline Absent (82) & 163.5 & 138.7 & 74.5 & 51.9 \\
\hline & $<0.001$ Significant & $<0.001$ Significant \\
\hline
\end{tabular}

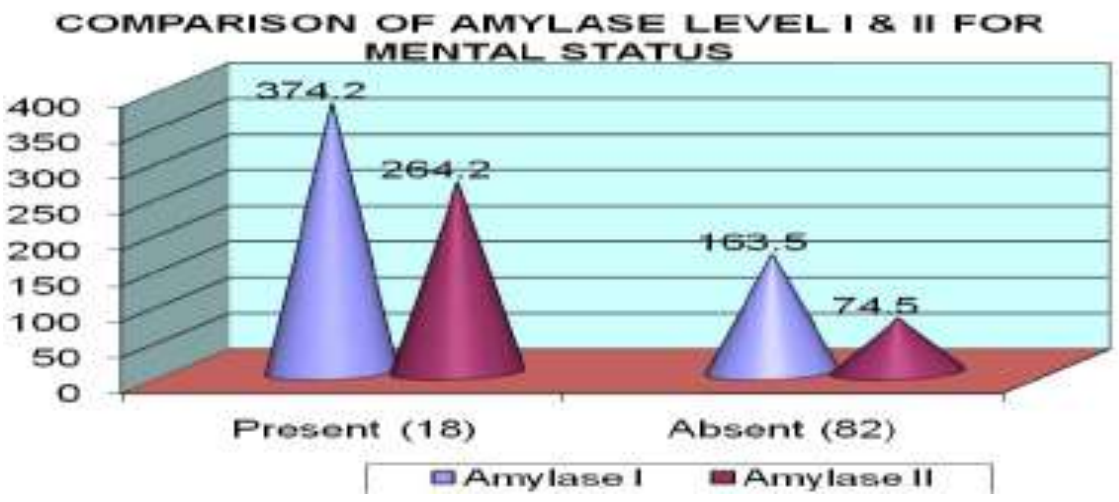

Comparision of amylase level $i$ and ii for fasciculaton :

\begin{tabular}{|l|l|l|l|l|}
\hline \multirow{2}{*}{ Fasciculation } & \multicolumn{2}{|l|}{ Amylase level I } & \multicolumn{2}{l|}{ Amylase level II } \\
\cline { 2 - 5 } & Mean & SD & Mean & SD \\
\hline Present (14) & 355.2 & 105.8 & 251.6 & 94.8 \\
\hline Absent (86) & 176.5 & 145.1 & 95.4 & 68.1 \\
\hline & $<0.001$ Significant & \multicolumn{2}{l}{$<$} \\
\hline
\end{tabular}






Comparision of amylase level $i$ and ii for respiratory failure :

\begin{tabular}{|l|l|l|l|l|}
\hline \multirow{2}{*}{$\begin{array}{l}\text { Respiratory } \\
\text { failure }\end{array}$} & \multicolumn{2}{|l|}{ Amylase level I } & \multicolumn{2}{l|}{ Amylase level I } \\
\cline { 2 - 5 } & Mean & SD & Mean & SD \\
\hline Present (21) & 327.9 & 133.7 & 217.6 & 111.5 \\
\hline Absent (79) & 167.8 & 140.3 & 79.73 & 59.8 \\
\hline & 0.001 Significant & -0.001 Significant \\
\hline
\end{tabular}

\section{COMPARISON OF AMYLASE LEVEL I \& II FOR RESPIRATORY FAILURE}



Pancreatitis and its outcome

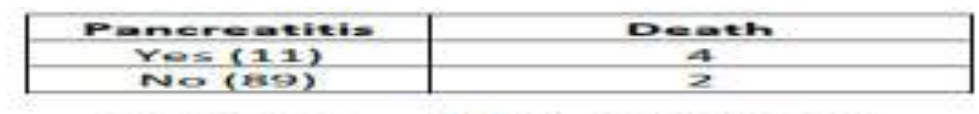



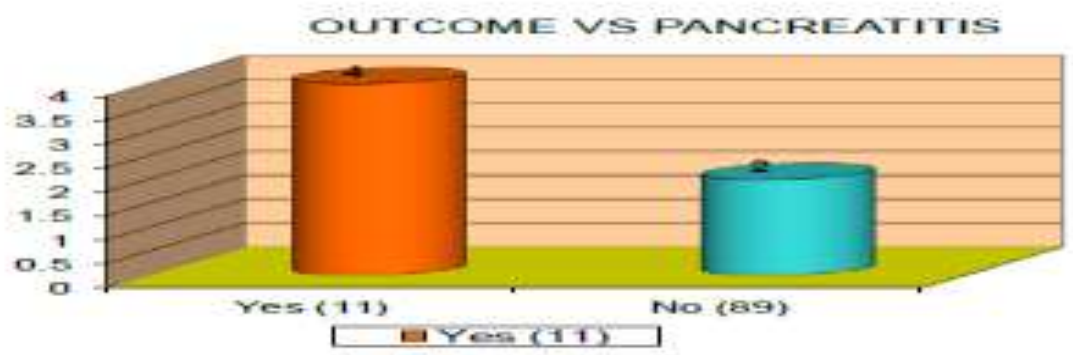




\section{Discussion}

Organophosphate and Carbamates are frequently used pesticides which can produces life threatening intoxication. Well over 50000 organophosphorous compounds have been synthesized. The mechanism of action is irreversible inactivation of acetylcholinesterase enzyme (Ach).

The clinical feature varies from cholinergic crisis, muscle paralysis, seizure, respiratory failure to death. The maximum mortality i.e around $90 \%$ seen in developing countries specially among farmer or related to farm works.

With the ease of availability, it is not surprising that the use of Organophosphate compounds in suicide attempts has mushroomed from a disturbing early trend to being one of the commonest mode of suicidal poisoning which accounted for $100 \%$ in our study.

No accidental exposure in our study. This alarming incidence of suicide attempts, may be probably due to uncontrolled scale and use of these agents all over the country.

A prospective study was done by the Department of Internal Medicine, University of Yuzuncu yil, medical faculty, van turkey in 2002 to find the prevalence of pancreatitis in OP poisoning. Four of the total 47 patients with acute OP poisoning had obviously elevated serum amylase and lipase level ( amylase $>300$ : lipase $>60 \mathrm{u} / \mathrm{l}$ ). only two of the patients with amylase level between 100-300 u/l had elevated level of lipase. None of the patients with normal lipase had elevated level of lipase. A total of $12.76 \%$ was diagnosed as acute pancreatitis. It was concluded that acute pancreatitis is not a rare complication of OP intoxication. In order to improve the outcome of OP intoxication early diagnosis of acute pancreatitis is important and serum amylase and lipase should be routinely considered.

In our study 11 out of total 100 patients with OP intoxication has significantly elevated ( >300 u/l ) amylase and significantly elevated $(>150 \mathrm{u} / \mathrm{l})$ lipase. None of the patients with normal amylase level has elevated serum lipase level. A total of $11 \%$ was diagnosed as acute pancreatitis.so as per our study also acute pancreatitis is not a rare complication of OP intoxication.

A prospective study was undertaken In Pgimer, Chandigarh, India between june 2001-june 2005 to find the incidence of hyperamylasemia and acute pancreatitis in patient with OP poisoning. Of the 79 patients studied, amylase was found to be elevated ( $>200$ s.u ) in 37 patients $(46.95 \%$ ). Among them in 3 patients it was 800 s.u. one of them showed swollen pancreas on USG abdomen and confirmed by CT abdomen. In other two patients, evidence of pancreatitis was not observed. There was no significant correlation between the nature of compound, duration and severity of cholinergic syndrome and increase in amylase level. It has been concluded that mild elevation is common in patients with OP poisoning, however acute pancreatitis is rare.

A retrospective study of medical records of 121 patients with the diagnosis of OP poisoning over 3 years was done in veterans general hospital, national yangming university in 1998. Serum amylase, pancreatic amylase, salivary amylase, lipase and cholinesterase level and the clinical manifestation were analyzed. It was observed that 44 patients (36\%) had hyperamylasemia (>360u/l), lipase was measured in 28 patients with hyperamylasemia, 9 out of 28 had hyperlipasemia (lipase $>360 \mathrm{u} / \mathrm{l}$ ). the finding of hyperamylasemia was closely related to clinical severity and presence of shock.

However, hyperamylasemia is not synonymous with acute pancreatitis and pancreatic amylase in not reliable parameter in the diagnosis of organophosphate poisoning induced pancreatitis. So lipase assay is indicated with hyperamylasemia for diagnosis of pancreatitis.

On analysing this study

\section{Summary}

There were 75 male and 25 female patients in the group. The mean age of the patient group is $40 \pm 9$ years.

Most common OP intoxication is methyl parathion

Most common mode of intoxication is with water

Most common reason for intoxication is familial.stress

Age and sex is not significantly correlated with OP intoxication and its severity and complications.

DOI: 10.9790/0853-1509067198

www.iosrjournals.org

96 | Page 
- Marked Muscarinic symptoms are

1)secretions $(87 \%)$

2)miosis (57\%)

3)respiratory failure $(21 \%)$

- Marked nicotinic symptom is fasciculation (14\%)

- Marked CNS symptom is depressed mental status (17\%)

- Significantly Elevated amylase (300 u/l) level : 36\% (p o.oo1)

- $\quad$ Significantly Elevated lipase (>150 level) : 11 out of 100 ( Acute pancreatitis )

- USB abdomen : Acute pancreatitis $11 \%$ and normal in $89 \%$ cases

- Pancreatitis without respiratory failure : 2 out of 11

- Pancreatitis with respiratory failure : 9

- Death without pancreatitis due to respiratory failure : 2 out of 89

- Death with pancreatitis with respiratory failure : 2 out of 9

- Death with pancreatitis without respiratory failure : 2 out of 11

\section{Conclusion}

So from our study it is estimated that for every patient with Organophosphate intoxication we have to do screening for pancreatitis with the help of serum amylase and serum lipase and for confirmation USG abdomen.

Our study also shows that there was a significant correlation between markedly increased serum amylase and serum lipase and respiratory failure and their outcome.

\section{Bibliography}

[1]. Sahin aslan,MD,Zeynep cakir, MD,Mucahit emet, MD, Mustafa Serinken,MD ,hayati kandis,MD, and Mustafa uzkeser,MD doi:10.1016/j.jemermed.2010.05.072.

[2]. Dr abhay nath chaturvedi,dr soumyakanti dutta,dr sanjay, dr tushar kanti saha,dr subhajyoti adhikary, dr sukdeb das, dr mitali basu:www.iosrjournal.org

[3]. Dr subhash vijay kumar,md. Fareedullah,sudhakar,b. venkateswarlu,Vaagdevi college of pharmacy,dept. of pharmacy practice, Warangal,AP

[4]. Dr sahin,onbasi,karakaya,in hum exp toxicology 2012

[5]. Lee WC,yang cc,dang jf,wu ML, lin HU:J TOXICOL CLIN TOXICOL 1998

[6]. Ahmed A ,begam I,aquil Natif s,Hussain tvohra ea:PAK J MED SCI OCTOBER-DECEMBER 2009(PART-2 VOL-25 NO 6

[7]. M eddlestron, 1 szinicz,p eyer,oximes in acute OP PESTICIDES poisoning;QJ MED.J.2002;275-238

[8]. M.A Cherian,c. roshini,j visalakshi.JAP1 MAY 2005;53;427-430

[9]. Cholinergic toxicology syndrome,www.google.com

[10]. Michotte a,van dijck 1,mals. v.JIFCC 1999;11(2)

[11]. C.H Srinivas rao,v vankatesvarlu,t surrender,pesticide in south india opportunities for prevention and improved medical management.TROPICAL MEDICINE AND INTERNATIONAL HEALTH JUNE 2005.10(6);581-588

[12]. Extonent -cholinestrase inhibition

[13]. K d tripathi,essential of medical pharmacology.8th edition

[14]. Pesticide illness

[15]. Vidyasagar,j. karunagar n,reddy ms.oxidative stress and antioxidant status in acute OP poisoning

[16]. Kushik jaga,chandrabhan dharmani,sourse of exposure to and public health implications of OP poisoning REV.PANAM SALUD PUBLICA 2033;14(3)171-185

[17]. SINGH S,SHARMA N.neurological syndromefollowing OP poisoning NERRO INDIAN (SERIAL ONLINE)2000;48;308-13

[18]. Toxicity,OPC AND CARBAMATES,WWW.EMEDICINE.COM/EMERGENCY

[19]. Murat sungur,mohammed guiven.intensive care management of OP poisoning CRIT CARE 2001;5(4)211-215 
“A Study On Serum Amylase Level And Prevalence Of Acute Pancreatitis In .....
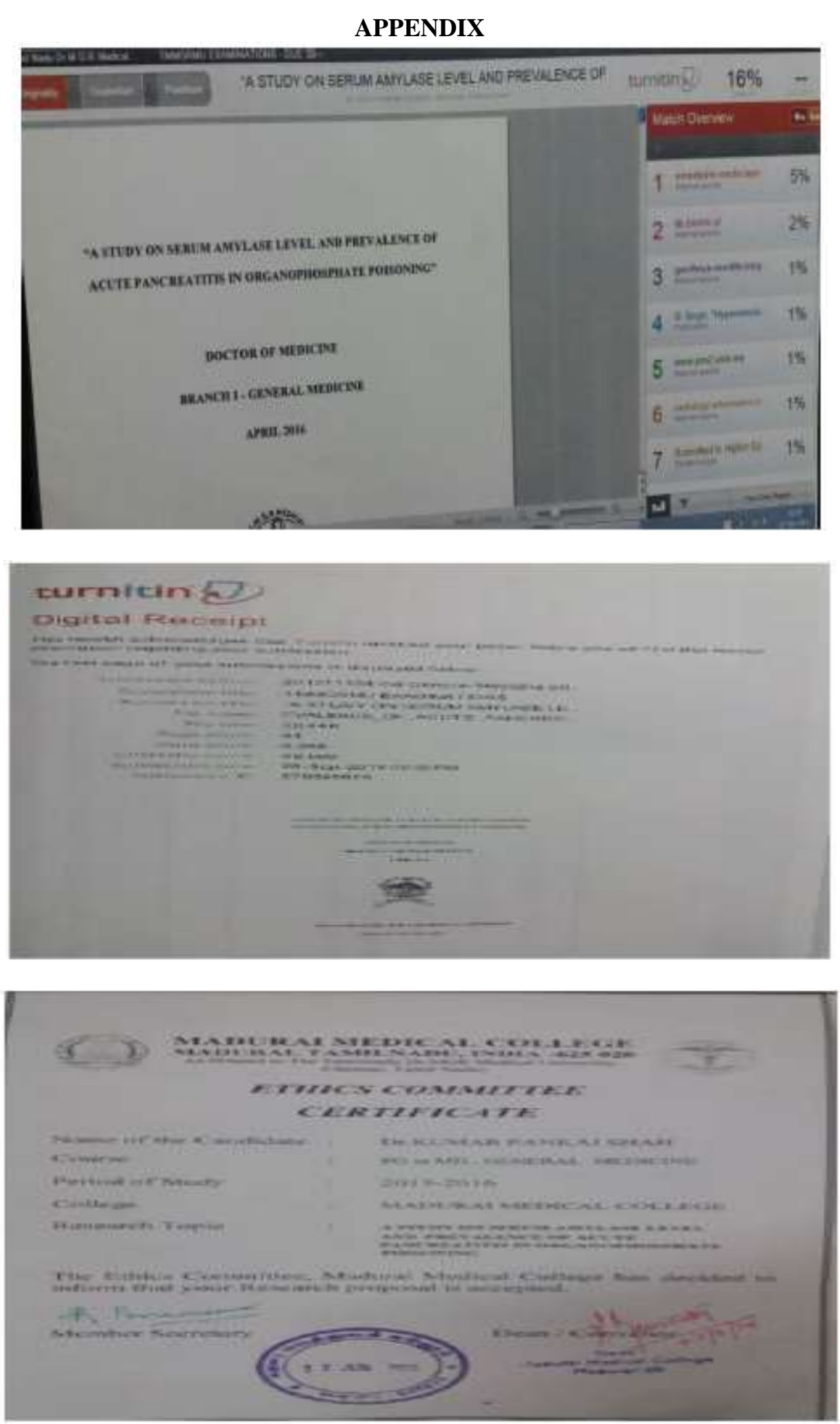